Scientific Review - Engineering and Environmental Sciences (2021), 30 (1), 159-170

Sci. Rev. Eng. Env. Sci. (2021), 30 (1)

Przegląd Naukowy - Inżynieria i Kształtowanie Środowiska (2021), 30 (1), 159-170

Prz. Nauk. Inż. Kszt. Środ. (2021), 30 (1)

http://iks.pn.sggw.pl

DOI 10.22630/PNIKS.2021.30.1.14

Ali Subhi ALHUMAIMA, Sanjar Mutalovich ABDULLAEV

South Ural State University, Department of System Programming

\title{
The sensitivity of vegetation in the lower Tigris basin landscapes to regional and global climate variability
}

Key words: climate variability, vegetation, global modulation, precipitation, temperature

\section{Introduction}

Global climate change has the potential to increase the frequency of ecosystem disturbances such as fire and drought, threatening the terrestrial ecological environment and food security (Yuan, Wu, Hou, Xu \& Lu, 2019). Most of the Euphrates-Tigris basin, especially in southeastern Turkey as well as in northern Syria and Iraq (the lower Tigris basin), has a Mediterranean climate that is characterized by wet winters and dry summers (Food and Agriculture Organization of the United Nations [FAO], 2009). Hence, the vegetation of the region is highly sensitive to climatic variability (Alhumaima \& Abdullaev, 2019).

Since the 1970s, monitoring vegetation has been improved using several remote sensing-based indices. The normalized difference vegetation index (NDVI)
(Tucker, 1979), specifically, is the most popular and has been used successfully to detect vegetation and climate conditions interactions worldwide at various temporal and spatial scales (Wu et al., 2015; Xu, Yang \& Chen, 2016; Yuan et al., 2019; Luo, Mao, Wen \& Liu, 2020). In the study of Luo et al. (2020), the dynamic characteristics of drought characterized using the standardized precipitation evapotranspiration index (SPEI) and the $N D V I$ were investigated and evaluated on an interannual scale from 1998 to 2015. Two NDVI datasets were used in the work of Xu et al. (2016) to study vegetation growth and its response to climate change reflected by the precipitation, minimum, maximum, and mean temperatures at yearly and monthly time scales from 1982 to 2013. Yuan et al. (2019) established the trend of NDVI vegetation change in the past three decades (1982-2013) and examined the effect of climate (monthly temperature and precipitation) and non-climate (population, gross domestic product, and live- 
stock) factors on vegetation growth. Note that the temporal delay in the vegetation response to environmental changes should be considered when looking for the sensitivity of ecosystems to climate variability ( $\mathrm{Wu}$ et al., 2015). However, in our recent work (Alhumaima \& Abdullaev, 2019), found that the maximum biological productivity during the growing season for Diyala river basin, a tributary of Tigris, is controlled by seasonal winter precipitation and January-March mean temperatures. Also showed that the neural network-based prediction of the spatiotemporal NDVI can be improved by using additional zonal landscape input predictor or by constructing an individual predicting model for each one of the zonal landscapes.

The two main aims of this study are (a) to establish the temporal vegetation change during the maximum biological productivity season and (b) to explore the vegetation sensitivity to recent (2000-2016) climate variability. However, direct regional observations of precipitation and temperatures are very rare and sparse, i.e. they cannot provide the needed spatiotemporal series. A particularly attractive option is to use the available different climate factors from several global gridded datasets. In this work, we compared the NDVI response to precipitation and temperature time series derived from seven observational and reanalysis datasets. These data have rarely been used for the lower Tigris basin; therefore, it would be beneficial to assess their performance in reflecting the vegetation variability in the region. The significant differences in climatic conditions of the different datasets led us, first, to use normalized versions of them, and second, to refuse the using of Köppen-Trewartha bioclimatic classification. Instead, landscapes were classified based on land cover/use categories and altitude levels. To compensate for the absence of some other factors on which the biological productivity of the landscapes depends, such as wind speed, cloudiness, etc., the impact of global weather-forming factors, expressed in global circulation indices, has been assessed also.

\section{Materials and methods}

\section{Study area}

Thestudyarea ofapprox. $251,400 \mathrm{~km}^{2}$ $\left(41^{\circ} 05^{\prime}-48^{\circ} 07^{\prime} \mathrm{E}\right.$ and $\left.38^{\circ} 38^{\prime}-48^{\circ} 07^{\prime} \mathrm{N}\right)$ illustrated in Figure 1; is distributed mainly between Iraq, Iran and Turkey and includes the basins of the five major tributaries of Tigris: Fesh Khabour, Greater Zab, Lesser Zab, Al-Adhaim and Diyala. The region has diverse landforms (Fig. 1b) and land cover patterns (Fig. 1c) that are expected to be very sensitive to climate variability. From the total study area, $22 \%$ are plains with heights of up to $300 \mathrm{~m}, 32 \%$ are foothills with elevations from 300 to $900 \mathrm{~m}$ and the remaining $46 \%$ are mountainous regions. From the land cover map, $47 \%$ of the study area is occupied by natural vegetation (NV: grasslands, trees, shrubs, and herbaceous vegetation), $33 \%$ is attributed to agricultural croplands which are classified into agricultural rainfed lands (AR: 25\%) and agricultural irrigated lands (AI: 8\%), and low vegetation lands (LV: sparse vegetation, barren, water bodies and urban). 


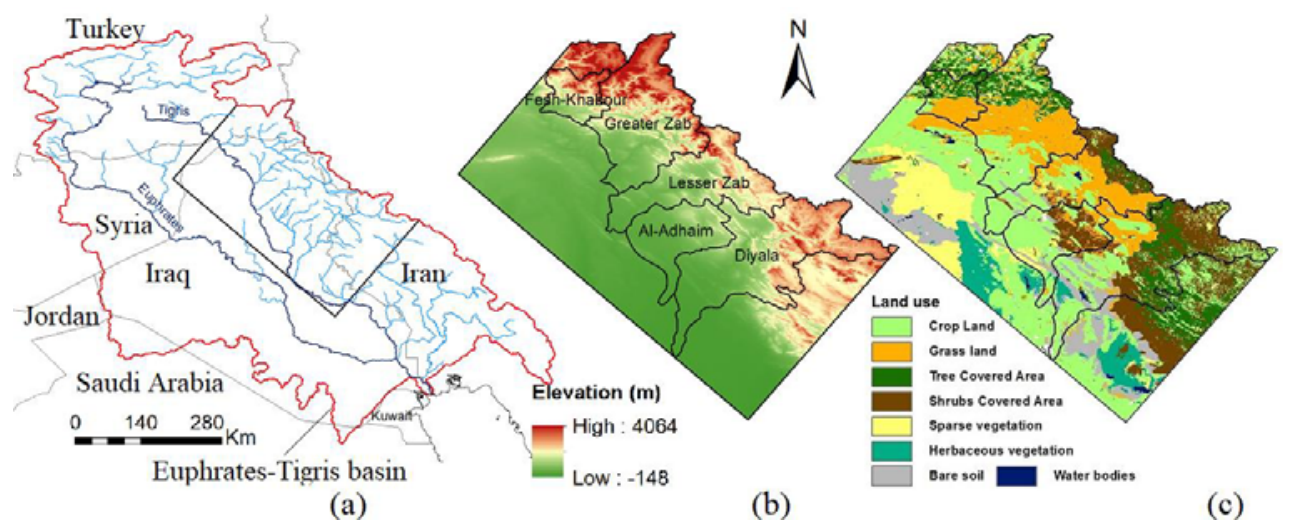

FIGURE 1. Study area (a) with elevation levels (b) and land cover map (c)

\section{Datasets}

Ten gridded datasets were used in this study. The MODIS 16-day NDVI maps of $250 \times 250 \mathrm{~m}$ spatial resolution and 16 days temporal resolution (MOD13Q1) (Didan, 2015) for March and April growing months were directly downloaded from NASA's Earth Observing System. In addition, we used the ASTER GDEM version 2 (Ministry of Economy, Trade and Industry of Japan / United States National Aeronautics and Space Administration [METI/NASA], 2011) and FAO Global Land Cover-SHARE version 2014 (Latham, Cumani, Rosati \& Bloise, 2014) datasets to delineate the different terrains and land cover types, and thus construct study area landscapes.

The monthly precipitation and temperature data used over the period 1981-2016 were obtained from two observational and five atmospheric reanalysis datasets: CRU-TS4.01 (Harris, Jones, Osborn, \& Lister, 2014), UDV5.01 (Willmott \& Matsuura, 2019), ERA-Interim (Dee et al., 2011), Modern-Era Reanalysis 2 (Gelaro et al., 2017), NCEP-DOE AMIP-II Reanalysis
(Kanamitsu et al., 2002), JRA-55 (Kobayashi et al., 2015) and NCEP-CFSR (Saha et al., 2014), hereafter CRU, UD, ERA, MERRA, NCEP, JRA and CFSR, respectively.

In addition, non-gridded datasets of global circulation indices: El-Nińo-Southern Oscillation (ENSO), Atlantic Multidecadal Oscillation ( $A M O)$, North Atlantic Oscillation $(N A O)$ and Dipole Mode Index $(D M I)$, obtained from the National Oceanic and Atmospheric Administration $(N O A A)$, were also used in this study.

\section{Study area landscapes}

From the above description, the study area has diverse ecosystems and land cover categories, and one could easily expect that their vegetation sensitivity to climate will be different. For this reason and in order to examine the effect of climate variability on the different NDVI landscapes, we classified our study area into 10 smaller landscapes (Fig. 2a): plains with NV, AR, AI and LV (PNV, PAR, PAI and PLV, respectively), foothills with NV, AR and LV (FNV, 
FAR and FLV, respectively), and finally mountains with NV, AR and LV (MNV, MAR and MLV, respectively). The mean altitude and area percentage of each individual landscape are illustrated in Figures $2 \mathrm{~b}$ and $2 \mathrm{c}$. Note that, in our analysis, LV landscapes, urban, and water areas were not considered. etated (Xu et al., 2016; Alhumaima \& Abdullaev, 2019).

\section{Standardized precipitation index and $z$-score}

To minimize the significant variance in the original amplitudes of the climate factors between the different datasets, only normalized time series of monthly

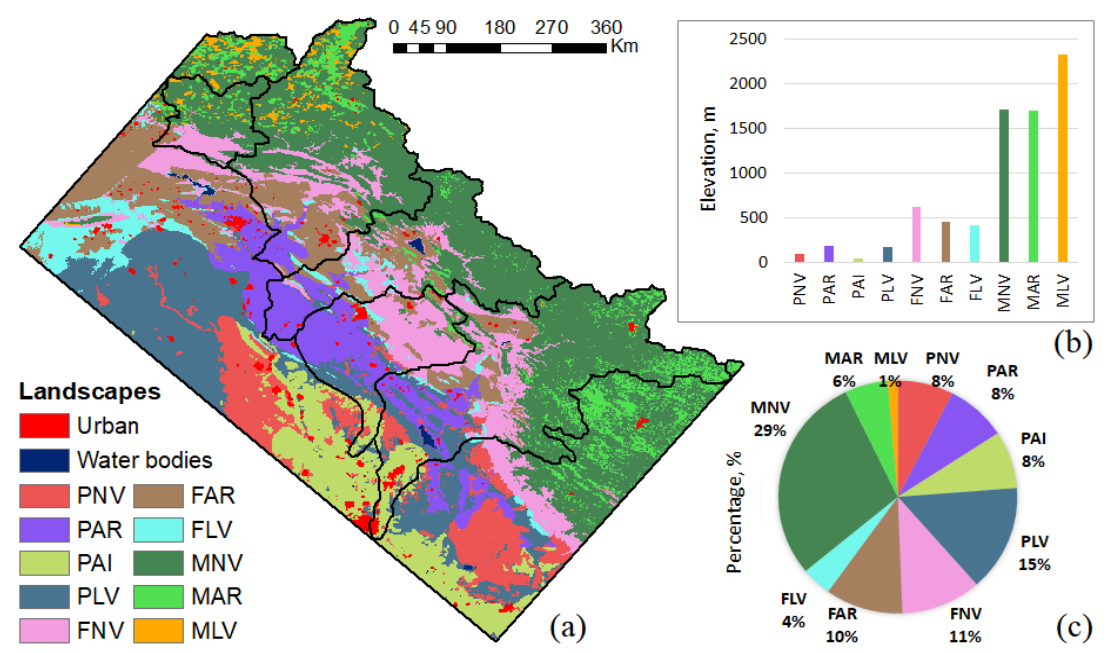

FIGURE 2. Study area landscapes (a) with their mean altitudes (b) and area percentages (c)

\section{Methods}

\section{NDVI data processing}

The maximum value compositing (MVC) method was used to produce monthly NDVI maps and minimize the effects of atmospheric, cloud contamination, and solar zenith angle (Alhumaima \& Abdullaev, 2019). Additionally, NDVI pixels less than 0.1 were excluded from the analysis and considered as non-veg- precipitation and temperatures have been used in this study. Therefore, we constructed for each individual landscape, seven pairs (based on the seven climate datasets) of 35-years (1981-2016) based time series of six-months (October-March) the standardized precipitation index (SPI) (Mckee, Doesken, \& Kleist, 1993; Alhumaima \& Abdullaev, 2018) and three-months (January-March) temperature $z$-score (Alhumaima \& Abdullaev, 2018; Li, Li, Lu, Zhang \& Kim, 2019). 


\section{Pearson correlation analysis}

Since the indices time series for the NDVI, global circulations, precipitation and temperatures meet the basic assumptions of parametric linear analysis, we decided to use the Pearson correlation coefficient (PCC) (Luo et al., 2020) to give a clear picture of the strength of the relationships among them. The preliminary correlation analysis showed that the NDVI vegetation of both March and April, averaged over the entire region, have the highest correlation $(0.5 \leq P C C$ $<0.8)$ to the same cumulative amounts of October-March period total precipitation and January-March period mean temperatures according to the seven climate datasets. Similarly, the coefficients of determination (Kamble, Kilic \& Hub-

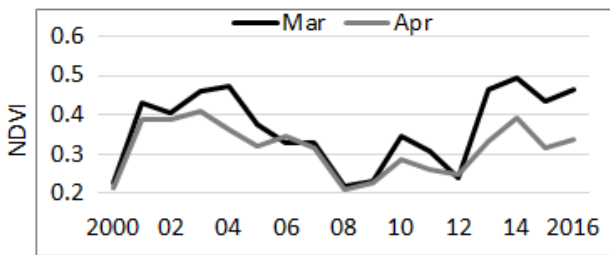

(a)

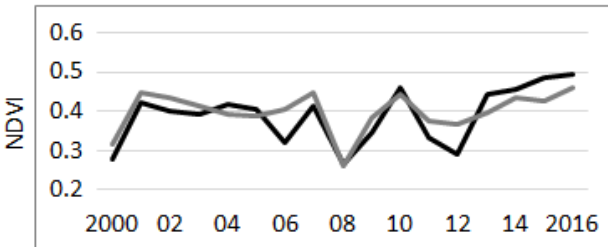

(c)

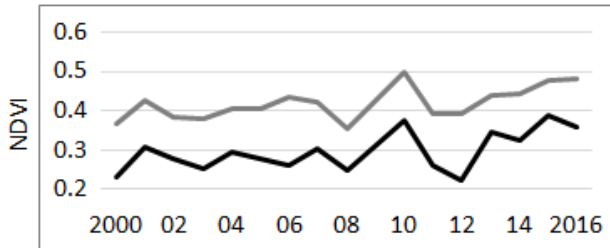

(e) bard, 2013), denoted $R^{2}$, were to measure the proportion of variability in the landscapes' $N D V I$ that can be explained by the other independent variables in the linear regression model.

\section{Results and discussion}

\section{Landscapes' NDVI change}

The NDVI time series for six regional landscapes during March and April growing months are illustrated in Figure 3. These time series are not regular over the study period with the presence of almost significant lack in vegetation during 2000, 2006, 2008, 2009, 2011 and 2012. In fact, many previous studies reported that the Euphrates-Tigris basin

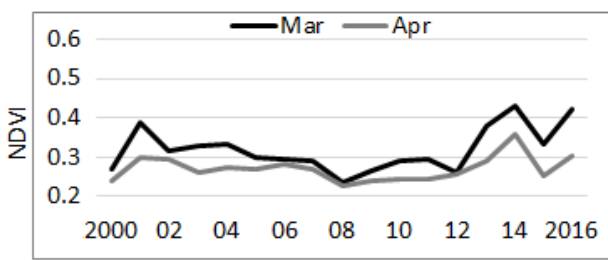

(b)

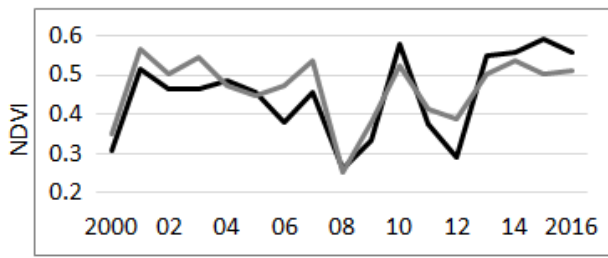

(d)

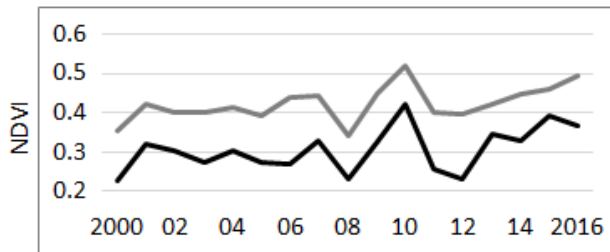

FIGURE 3. March and April mean NDVI of PAR and PAI (a and b), FNV and FAR (c and d), and MNV and MAR (e and f), respectively 
experienced significant drought events during these years (Alhumaima \& Abdullaev, 2018; Mathbout, Lopez-Bustins, Martin-Vide, Bech \& Rodrigo, 2018). At the same time, the moderate-high correlations between March NDVI time series of all regional landscapes with each other $(0.5 \leq P C C<1)$, confirm the effect of drought on all landscapes simultaneously. The correlations between landscapes' March NDVI and those of April were moderate to high $(0.5 \leq P C C<1)$ also. On the other hand, these correlations indicate different responses from different landscape types.

The NDVI change in the agricultural rainfed landscapes (PAR for example, Fig. 3a) during both March and April were more prominent and less stable ( $s t d=0.103$ and 0.066 ) compared to that of the agricultural irrigated landscape (PAI, Fig. 3b) which was more stable but also observable ( std $=0.062$ and 0.032 , respectively). This indicates that the croplands are also affected by climatic variability, but human management, such as; irrigation could mitigate the negative effects.

\section{Landscapes sensitivity to climate}

The 35-years based mean monthly precipitations averaged over the whole study area (Fig. 4a) show that UD, ERA, JRA, and CFSR, with annual precipitations of 451, 462, 620 and $470 \mathrm{~mm}$, were wetter than CRU, MERRA and NCEP of 375,257 and $395 \mathrm{~mm}$, respectively. At the same time and with respect to the temperatures (Fig. 4b), the mean annual values were ranged between 17.8 and $18.4^{\circ} \mathrm{C}$, except for NCEP and JRA datasets of only 12.8 and $14.3^{\circ} \mathrm{C}$, respectively.
Several studies showed that significant differences exist in precipitation estimates between the different datasets and their performance may vary depending on the geographic location and climatic zone (Essou, Sabarly, Lucas-Pither, Brisette \& Poulin, 2016; Chen, Gan, Tan, Shao \& Zhu, 2019). We demonstrated in Alhumaima and Abdullaev (2018) that despite their relative simplicity, the $S P I$ and $z$-score are good indicators of regional drought/wet and cold/warm cases, respectively. The 17 out of the 35 -years based $z$-score time series of January-March period temperatures (ZJM) calculated over three of the regional landscapes and analogous sixmonth SPI time series of October-March period precipitation (SPIOM) are shown in Figures 4c, 4d, 4e, 4f, 4g and 4h.

However, we examined the correlations between NDVI in March and April of each individual landscape and the corresponding normalized climate factors and found that there are large variances in these relationships $(0.17 \leq P C C<0.91)$ depending on dataset used and landscape type. For example, March NDVI in of the foothills' natural vegetation landscape (FNV, Fig. 3e) has weak correlations $(P C C<0.5)$ with SPIOM according to UD and JRA datasets, moderate correlations $(0.5 \leq P C C<0.75)$ according to CRU, ERA, NCEP and CFSR datasets, and high correlation $(P C C \geq 0.75)$ according to MERRA dataset. The correlations between March NDVI of the same landscape and ZJM were moderate (high) according to CRU, UD, ERA, MERRA, NCEP and CFSR (JRA).

To estimate how much March NDVI variability is associated with both SPIOM and ZJM according to the seven datasets, 

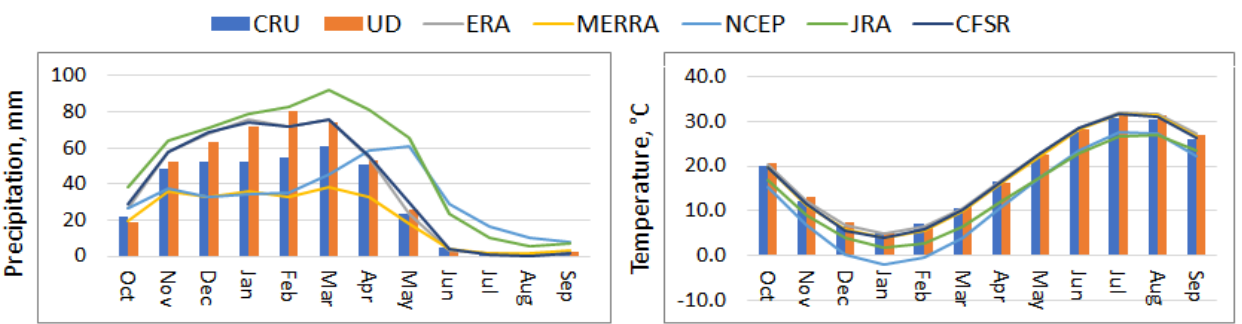

(a)
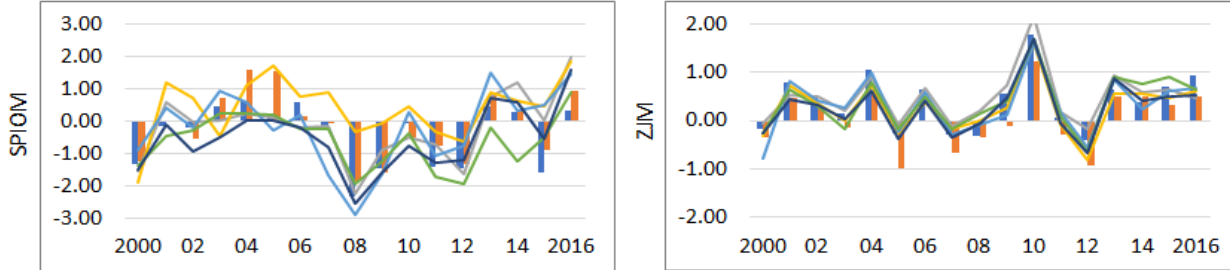

(c)
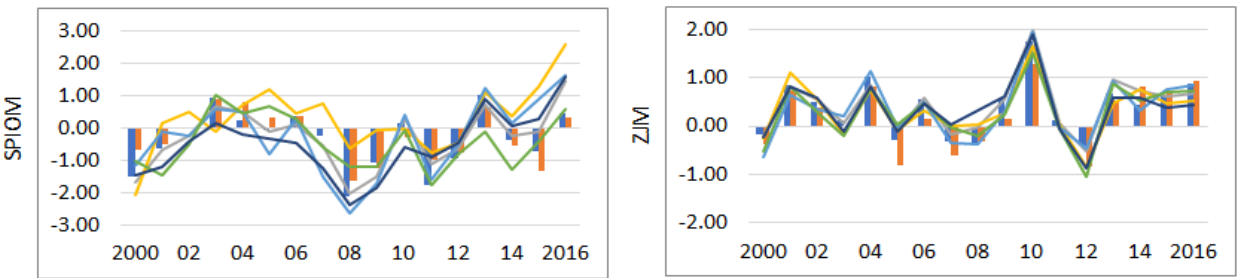

(e)

(f)

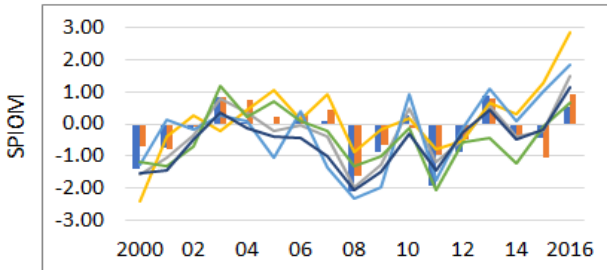

(g)

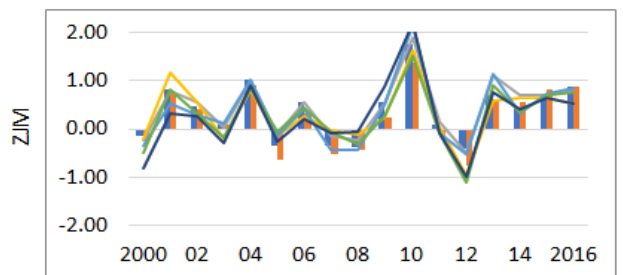

(h)

FIGURE 4. Study area mean annual precipitations and temperatures (a and b); normalized monthly precipitations and temperatures of PAR, FNV and MNV landscapes (c-d, e-f and g-h), respectively, according to seven datasets

we calculated the coefficients of determination $\left(R^{2}\right)$. The $R^{2}$ values, presented in the table, are directly interpreted as follows. If the value of $R^{2}$ is 0.40 , as in the case of PNV landscape (depending on SPIOM and ZJM of JRA reanalysis), this means that $40 \%$ of the original variability of NDVI can be explained by the corresponding hydrothermal regime, and $60 \%$ of residual variability remains unexplained.

The table indicates that the variability of landscapes' NDVI, explained using two normalized climatic factors of the same dataset, is varied between 28 and $83 \%$ depending on the dataset used. However, using the time series of ERA and CFSR, we can explain from 
TABLE. Relative part of landscapes' $N D V I$ variability described by variations of normalized seasonal precipitation and temperatures

\begin{tabular}{|c|c|c|c|c|c|c|c|c|c|}
\hline \multirow{2}{*}{ LS } & \multicolumn{6}{|c|}{ Resulted $R^{2}$ values based on SPIOM/ZJM of the same } & \multicolumn{2}{c|}{ Using mixed datasets } \\
\cline { 2 - 12 } & CRU & UD & ERA & MERRA & NCEP & JRA & CFSR & SPIOM/ZJM & $R^{2}$ \\
\hline PNV & 0.48 & 0.62 & 0.80 & 0.45 & 0.48 & 0.40 & 0.69 & ERA/CFSR & 0.82 \\
\hline PAR & 0.55 & 0.65 & 0.74 & 0.52 & 0.69 & 0.49 & 0.77 & CFSR/UD & 0.79 \\
\hline PAI & 0.40 & 0.46 & 0.83 & 0.28 & 0.53 & 0.34 & 0.77 & ERA/UD & 0.86 \\
\hline FNV & 0.54 & 0.56 & 0.65 & 0.78 & 0.61 & 0.61 & 0.72 & MERRA/UD & 0.80 \\
\hline FAR & 0.61 & 0.71 & 0.71 & 0.77 & 0.72 & 0.67 & 0.75 & CFSR/MERRA & 0.83 \\
\hline MNV & 0.54 & 0.58 & 0.63 & 0.78 & 0.61 & 0.69 & 0.69 & MERRA & 0.78 \\
\hline MAR & 0.63 & 0.61 & 0.68 & 0.80 & 0.65 & 0.71 & 0.72 & MERRA & 0.80 \\
\hline
\end{tabular}

77 to $83 \%$ of $N D V I$ variability on lowland plains' landscapes and from 63 to $75 \%$ on higher landscapes. The MERRA dataset is poorest to describe the variability of the semi-desert plains' vegetation $(28-45 \%)$ but it is the best predictor for foothills' and mountains' vegetation (77-80\%). Thus, the consideration of the combined effects of normalized seasonal precipitation and temperature exposure to vegetation explains much of $N D V I$ variability, regardless of geographic location and land cover type.

To obtain better predictions, we calculated $R^{2}$ for each individual landscape based on all possible combinations of SPIOM and ZJM time series from the different datasets. The results (the table) showed that the explanation of NDVI variability of four out of the five landscapes, located in plains and foothills (PNV, PAR, PAI and FNV), optimized by $2.4-3.5 \%$ using ZJM time series of CFSR and UD datasets, while the combination of SPIOM and ZJM time series of CFSR and MERRA datasets, respectively, to explain $N D V I$ variability of the FAR landscape has increased $R^{2}$ by $7.2 \%$. This clearly indicates that better predictions of vegetation variability can be obtained when relying on more than one dataset simultaneously.

From the above analysis, vegetation of the region is highly dependent on climate. Therefore, it makes sense to link factors that affect the regional climate with the vegetation. On the other hand, these factors could compensate for the absence of other factors like wind speed, total cloud cover, evaporation, soil moisture and many others that have an effect on plant growth. However, in this work, we decided to verify from the states of ENSO, AMO, NAO and DMI as it has been found in several studies (Cullen, Kaplan, Arkin \& de Menocal, 2002; Karabörk \& Kahya, 2009; Khidher \& Pilesjö, 2015; Pourasghar, Oliver \& Holbrook, 2019) that they have a significant influence on climate and rivers' streamflow in the surrounding areas.

The analysis showed that the study area's averaged SPIOM according to all datasets are moderately correlated $(0.55$ $\leq P C C \leq 0.7)$ to both: SON, OND, NDJ and DJF states of ENSO and December state of $D M I$, while the correlations were weak with both $N A O$ and $A M O$. 
We found that the ZJM temperatures are moderately correlated $(0.5 \leq P C C \leq 0.6)$ to SON state of $A M O$, while the correlations were weak with other indices.

As expected, the correlation analysis between March NDVI and the four global circulation indices showed that the most positive responses of landscapes were also to the SON-DJF states of ENSO $(0.55 \leq P C C \leq 0.70)$ and December state of $D M I(0.37 \leq P C C \leq 0.72)$. With respect to the SON state of $A M O$ and $N A O$, the responses of all landscapes were weakly positive $(0.17 \leq P C C \leq$ $0.36)$ and weakly negative $(-0.34 \leq P C C$ $\leq-0.1)$, respectively. For the correlations with the next April, almost the same description above has noted but with less sensitivity compared to March.

As with the NDVI, SPIOM and ZJM, we calculated the coefficients of determination based on all possible combinations of the four circulation indices in order to find out the best predictors for each of the regional landscapes. The analysis showed that using the combined effect of three sets of circulation indices (ENSO, AMO and NAO; ENSO,DMI and NAO; ENSO, DMI and AMO) we can explain $30-55,70-78$, and $60-64 \%$ of landscapes' $N D V I$ variability on plains, foothills, and mountains, respectively.

Thus, it can be concluded from the results that the consideration of the combined effects of the global circulation indices and climate factors can enhance the explanation of vegetation variation. To prove this, we recalculated $R^{2}$ based on five input predictors consisting of landscapes' best combinations of normalized climate factors (the table) and climate indices, and found that the relative explanations of $N D V I$ variability for all landscapes have increased by $4.5-9.5 \%$ compared to the values presented in the table. Here, $R^{2}$ of: plains' landscapes (PNV, PAR and PAI) have increased to be 86,84 and $93 \%$ with increasing rates of $4.7,6.0$ and $7.5 \%$, foothills' landscapes (FNV, FAR) have increased to be 88 and $89 \%$ with increasing rates of 9.1 and $6.7 \%$, and finally, mountainous landscapes (MNV, MAR) have increased to be 86 and $88 \%$ with increasing rates of 9.3 and $9.1 \%$, respectively.

\section{Conclusions}

In this work, the study area of the lower Tigris basin was classified based on the landforms (plains, foothills, and mountains) and land cover patterns (natural vegetation, agricultural rainfed, and agricultural irrigated) into 10 smaller natural and agricultural landscapes. The variation of remote sensing MODIS NDVI data was then examined during the maximum biological productivity season (March and April) as a response to the current regional and global climate variability. These latter are reflected by monthly precipitation and temperature time series derived from two observational and five reanalysis climate datasets (CRU, UD, ERA, MERRA, NCEP, JRA and CFSR) and four circulation indices (ENSO, AMO, NAO and DMI). The preliminary analysis showed the NDVI of both March and April are strongly correlated with the cumulative winter precipitation (October-March) and mean temperatures of January-March period. The significant differences in precipitation and temperature estimates between the different datasets led us to 
use normalized versions of the climate factors (SPI and $z$-score) in searching for the landscapes' vegetation response to climate variability. The multiple correlation analysis showed that combining the normalized seasonal climate factors from different datasets can explain much of the landscapes' $N D V I$ variability regardless of the geographic location and land cover category. It is also found that the predictability of landscapes' vegetation conditions can be enhanced by combining climate factors with global circulation indices that are found to influence the regional climate as well.

\section{References}

Alhumaima, A.S. \& Abdullaev, S.M. (2018). Preliminary assessment of hydrothermal risks in the Euphrates-Tigris basin: Droughts in Iraq. Bulletin of the South Ural State University, Series, Computational Mathematics and Software Engineering, 7(4), 41-58. https://doi.org/10.14529/cmse180403

Alhumaima, A.S. \& Abdullaev, S.M. (2019). Landscape Approach to Normalized Difference Vegetation Index Forecast by Artificial Neural Network: Example of Diyala River Basin. Bulletin of the South Ural State University, Series Computer Technologies, Automatic Control \& Radioelectronics, 19(3), 5-19. https://doi.org/10.14529/ctcr190301

Chen, S., Gan, T.Y., Tan, X., Shao, D. \& Zhu, J. (2019). Assessment of CFSR, ERA-Interim, JRA-55, MERRA-2, NCEP-2 reanalysis data for drought analysis over China. Climate Dynamics, 53(1-2), 737-757. https://doi. org/10.1007/s00382-018-04611-1

Cullen, H.M., Kaplan, A., Arkin, P.A. \& de Menocal, P.B. (2002). Impact of the North Atlantic Oscillation on Middle Eastern Climate and Streamflow. Climatic Change, 55(3), 315-338. https://doi.org/10.1023/ A:1020518305517

Dee, D.P., Uppala, S.M., Simmons, A.J., Berrisford, P., Poli, P., Kobayashi, S., Andrae,
U., Balmaseda, M.A., Balsamo, G., Bauer, P., Bechtold, P., Beljaars, A.C.M., van de Berg, L., Bidlot, J., Bormann, N., Delsol, C., Dragani, R., Fuentes, M., Geer, A.J., Haimberger, L., Healy, S.B., Hersbach, H., Hólm, E.V., Isaksen, L., Kíllberg, P., Köhler, M., Matricardi, M., McNally, A.P., Monge-Sans, B.M., Morcrette, J.J., Park, B.K., Peubey, C., de Rosnay, P., Tavolato, C., Thépaut, J.N. \& Vitart, F. (2011). The ERA-Interim reanalysis: configuration and performance of the data assimilation system. Quarterly Journal of the Royal Meteorological Society, 137(656), 553-597. https://doi.org/10.1002/qj.828

Didan, K. (2015). MOD13Q1 MODIS/Terra Vegetation Indices 16-Day L3 Global 250m SIN Grid, V006 [Data set]. NASA EOSDIS Land Processes DAAC. https://doi.org/10.5067/ MODIS/MOD13Q1.006

Essou, G.R.C., Sabarly, F., Lucas-Picher, P., Brissette, F. \& Poulin, A. (2016). Can precipitation and temperature from meteorological reanalyses be used for hydrological modeling? Journal of Hydrometeorology, 17(7), 1929-1950. https://doi.org/10.1175/JHM-D$15-0138.1$

Food and Agriculture Organization of the United Nations [FAO] (2009). AQUASTAT Transboundary River Basins - Euphrates-Tigris River Basin. Rome: Food and Agriculture Organization of the United Nations.

Gelaro, R., McCarty, W., Suárez, M.J., Todling, R., Molod, A., Takacs, L., Randles, C.A., Darmenov, A., Bosilovich, M.G., Reichle, R., Wargan, K., Coy, L., Cullather, R., Draper, C., Akella, S., Buchard, V., Conaty, A., da Silva, A., Gu, W., Kim, G.K., Koster, R., Lucchesi, R., Merkova, D., Nielsen, J.E., Partyka, G., Pawson, S., Putman, W., Rienecker, M., Schubert, S.D., Sienkiewicz, M. \& Zhao, B. (2017). The Modern-Era RetrospectiveAnalysis for Research and Applications, Version 2 (MERRA-2). Journal of Climate, 30(14), 5419-5454. https://doi.org/10.1175/JCLI-D$16-0758.1$

Harris, I., Jones, P.D., Osborn, T.J. \& Lister, D.H. (2014). Updated high-resolution grids of monthly climatic observations - the CRU TS3.10 Dataset. International Journal of Climatology, 34(3), 623-642. https://doi. org/10.1002/joc.3711 
Kamble, B., Kilic, A. \& Hubbard, K. (2013). Estimating Crop Coefficients Using Remote Sensing-Based Vegetation Index. Remote Sensing, 5(4), 1588-1602. https://doi. org/10.3390/rs5041588

Kanamitsu, M., Ebisuzaki, W., Woollen, J., Yang, S.K., Hnilo, J.J., Fiorino, M. \& Potter, G. L. (2002). NCEP-DOE AMIP-II Reanalysis (R-2). Bulletin of the American Meteorological Society, 83(11), 1631-1644. https://doi. org/10.1175/BAMS-83-11-1631

Karabörk, M.Ç. \& Kahya, E. (2009). The links between the categorised Southern Oscillation indicators and climate and hydrologic variables in Turkey. Hydrological Processes, 23(13), 1927-1936. https://doi.org/10.1002/ hyp.7331

Khidher, S.A. \& Pilesjö, P. (2015). The effect of the North Atlantic Oscillation on the Iraqi climate 1982-2000. Theoretical and Applied Climatology, 122(3-4), 771-782. https://doi. org/10.1007/s00704-014-1327-4

Kobayashi, S., Ota, Y., Harada, Y., Ebita, A., Moriya, M., Onoda, H., Onogi, K., Kamahori, H., Kobayashi, Ch., Endo, H., Miyaoka, K. \& Takahashi, K. (2015). The JRA-55 reanalysis: general specifications and basic characteristics. Journal of the Meteorological Society of Japan. Ser. II, 93(1), 5-48. https://doi.org/10.2151/jmsj.2015-001

Latham, J., Cumani, R., Rosati, I. \& Bloise, M. (2014). FAO Global Land Cover SHARE (GLC-SHARE) Beta-Release (version 1.0). Rome: Land and Water Division, Food and Agriculture Organization.

Li, F., Li, H., Lu, W., Zhang, G., \& Kim, J.C. (2019). Meteorological Drought Monitoring in Northeastern China Using Multiple Indices. Water, 11(1), 72. https://doi.org/10.3390/ w11010072

Luo, N., Mao, D., Wen, B. \& Liu, X. (2020). Climate Change Affected Vegetation Dynamics in the Northern Xinjiang of China: Evaluation by SPEI and NDVI. Land, 9(3), 90. https://doi.org/10.3390/land9030090

Mckee, T.B., Doesken, N.J. \& Kleist, J. (1993). The relationship of drought frequency and duration to time scales. Proceedings of the 8th Conference on Applied Climatology, American Meteorological Society, 17(22), 179-184.
Mathbout, S., Lopez-Bustins, J.A., Martin-Vide, J., Bech, J. \& Rodrigo, F.S. (2018). Spatial and temporal analysis of drought variability at several time scales in Syria during 1961-2012. Atmospheric Research, 200, 153-168. https:// doi.org/10.1016/j.atmosres.2017.09.016

Ministry of Economy, Trade and Industry of Japan / United States National Aeronautics and Space Administration [METI/NASA] (2011). Advanced Spaceborne Thermal Emission and Reflection Radiometer Global Digital Elevation Model - ASTER GDEM (version 2) [DEM data sets]. Retrieved from https://asterweb.jpl.nasa.gov/gdem.asp

Pourasghar, F., Oliver, E.C.J. \& Holbrook, N.J. (2019). Modulation of wet-season rainfall over Iran by the Madden-Julian Oscillation, Indian Ocean Dipole and El Nińo-Southern Oscillation. International Journal of Climatology, 39(10), 4029-4040. https://doi. org/10.1002/joc.6057

Saha, S., Moorthi, S., Wu, X., Wang, J., Nadiga, S., Tripp, P., Behringer, D., Hou, Y.T., Chuang, H., Iredell, M., Ek, M., Meng, J., Yang, R., Mendez, M.P., van den Dool, H., Zhang, Q., Wang, W., Chen, M. \& Becker, E. (2014). The NCEP Climate Forecast System Version 2. Journal of Climate, 27(6), 2185-2208. https://doi.org/10.1175/JCLI-D-12-00823.1

Tucker, C.J. (1979). Red and photographic infrared linear combinations for monitoring vegetation. Remote Sensing of Environment, $8(2)$, 127-150. https://doi.org/10.1016/00344257(79)90013-0

Willmott, C.J. \& Matsuura, K. (2019). Terrestrial Air Temperature and Precipitation: Monthly and Annual Time Series (1900-2017). Delaware: Department of Geography, University of Delaware.

Wu, D., Zhao, X., Liang, S., Zhou, T., Huang, K., Tang, B. \& Zhao, W. (2015). Time-lag effects of global vegetation responses to climate change. Global Change Biology, 21(9), 3520-3531. https://doi.org/10.1111/gcb.12945

Xu, Y., Yang, J. \& Chen, Y. (2016). NDVI-based vegetation responses to climate change in an arid area of China. Theoretical and Applied Climatology, 126(1-2), 213-222. https://doi. org/10.1007/s00704-015-1572-1

Yuan, W., Wu, S., Hou, S., Xu, Z. \& Lu, H. (2019). Normalized Difference Vegetation 
Index-based assessment of climate change impact on vegetation growth in the humidarid transition zone in northern China during 1982-2013. International Journal of Climatology, 39(15), 5583-5598. https://doi. org/10.1002/joc.6172

\section{Summary}

The sensitivity of vegetation in the lower Tigris basin landscapes to regional and global climate variability. This study investigates the lower Tigris basin's the normalized difference vegetation index (NDVI) sensitivity in 2000-2016 to regional climate variability reflected by the monthly precipitation and temperature time series of seven global datasets as well as to four global circulation indices. To examine the effect of climate variability on the different ecosystems, the study area has been classified into 10 smaller natural and anthropogenic landscapes based on landforms and land cover patterns. The preliminary analysis showed that the maximum biological productivity reflected by the NDVI of March and April has the highest correlation $(0.5-0.8)$ to the same cumulative amounts of October-March period total precipitation and January-March period mean temperatures according to all datasets. In addition, this article showed there is a correlation between landscapes' $N D V I$ and global modulation represented by the September-February state of El Nińo-Southern Oscillation (ENSO) (0.55-0.70) and December state of the dipole mode index $(D M I)(0.35-0.72)$. The significant differences in the original precipitation and temperature levels according to the different datasets have urged the use of normalized time series: $z$-score of temperatures and analogous six-months the standardized precipitation index $(S P I)$. However, the multiple correlation analysis showed that using ERA-Interim and NCEP-CFSR (MERRA-2) based climate factors can explain from 77 to $83 \%$ of the NDVI variability on lowland plains (on higher foothills and mountainous lands). We found also that these prediction percentages can be increased by $2.4-7.2 \%$ when using time series of precipitation and temperatures derived from different datasets, in addition to $4.5-9.5 \%$ increasing rates when using the global circulation indices as additional predictors.

\section{Authors' address:}

Ali Subhi Alhumaima

(https://orcid.org/0000-0003-0895-6413)

Sanjar Mutalovich Abdullaev

(https://orcid.org/0000-0003-0405-704X)

South Ural State University

Department of System Programming

Lenin prospekt, 76, Chelyabinsk 454080

Russian Federation

e-mail: alhumaimaali@gmail.com abdullaevsm@susu.ru 